\title{
Lipodystrophy due to peptidic growth factors deficiency
}

INSERM

\section{Source}

INSERM. (1999). Orphanet: an online rare disease and orphan drug data base.

Lipodystrophy due to peptidic growth factors deficiency. ORPHA:1979

Deficiency of the peptidic growth factors is characterized by loss of subcutaneous fat layers on the limbs, lipodystrophy in the face and trunk and scleroderma-like skin disorders (thickened skin on the palms and soles and skin pigment changes on the limbs and trunk). 